\title{
In-situ high-pressure $x$-ray diffraction study of zinc ferrite nanoparticles
}

\author{
S. Ferrari ${ }^{1}$, R. S. Kumar ${ }^{2}$, F. Grinblat ${ }^{1}$, J.C. Aphesteguy ${ }^{1}$, F. D. Saccone ${ }^{3}$ and D. Errandonea ${ }^{4}$
}

${ }^{1}$ Instituto de Tecnología y Ciencias de la Ingeniería "Ing. Hilario Fernández Long” (UBACONICET), Facultad de Ingeniería, Av. Paseo Colón 850, C1063ACV Ciudad Autónoma de Buenos Aires, Argentina

${ }^{2}$ Department of Physics and Astronomy, High Pressure Science and Engineering Center, University of Nevada Las Vegas, 4505 Maryland Parkway, Las Vegas, Nevada 89154-4002, USA

${ }^{3}$ Departamento de Física, Facultad de Ingeniería (UBA), Av. Paseo Colón 850, C1063ACV Ciudad Autónoma de Buenos Aires, Argentina

${ }^{4}$ Departamento de Fisica Aplicada, Institut Universitari de Ciència dels Materials, Malta Consolider Team, Universitat de Valencia, c/ Doctor Moliner 50, E-46100 Burjassot, Valencia, Spain

Keywords: Oxides; Nanostructure; X-ray diffraction; crystal structure; phase transitions

\begin{abstract}
We have studied the high-pressure structural behavior of zinc ferrite $\left(\mathrm{ZnFe}_{2} \mathrm{O}_{4}\right)$ nanoparticles by powder X-ray diffraction measurements up to $47 \mathrm{GPa}$. We found that the cubic spinel structure of $\mathrm{ZnFe}_{2} \mathrm{O}_{4}$ remains up to $33 \mathrm{GPa}$ and a phase transition is induced beyond this pressure. The high-pressure phase is indexed to an orthorhombic $\mathrm{CaMn}_{2} \mathrm{O}_{4}$-type structure. Upon decompression the low- and high-pressure phases coexist. The compressibility of both structures was also investigated. We have observed that the lattice parameters of the high-pressure phase behave anisotropically upon compression. Further, we predict possible phase transition around $55 \mathrm{GPa}$. For comparison, we also studied the compression behavior of magnetite $\left(\mathrm{Fe}_{3} \mathrm{O}_{4}\right)$ nanoparticles by X-ray diffraction up to $23 \mathrm{GPa}$. Spinel-type $\mathrm{ZnFe}_{2} \mathrm{O}_{4}$ and $\mathrm{Fe}_{3} \mathrm{O}_{4}$ nanoparticles have a bulk modulus of 172(20) $\mathrm{GPa}$ and 152(9) GPa, respectively. This indicates that in both cases the nanoparticles do not undergo a Hall-Petch strengthening.
\end{abstract}




\section{Introduction}

Spinel-structured oxides belong to a large family of compounds which include more than eighty different oxides [1]. These oxides are relevant for many technological applications. Zinc ferrite $\left(\mathrm{ZnFe}_{2} \mathrm{O}_{4}\right)$, the mineral Franklinite, is one of the members of this family. At ambient pressure (P), $\mathrm{ZnFe}_{2} \mathrm{O}_{4}$ has a cubic spinel structure (space group $F d \overline{3} m$ ) [2], which is shown on the left side of Fig. $1 . \mathrm{ZnFe}_{2} \mathrm{O}_{4}$ is a normal spinel, which has a unit cell with 32 oxygen atoms in a close cubic packing arrangement, and 8 tetrahedral (T) and 16 octahedral (M) sites, occupied by $\mathrm{Zn}^{2+}$ and $\mathrm{Fe}^{3+}$ atoms, respectively.

There is a large interest on the study of spinel oxides under compression. The high pressure (HP) study of $\mathrm{ZnFe}_{2} \mathrm{O}_{4}$ has attracted attention for nearly half a century, since it was proposed that superparamagnetism can be induced by squeezing zinc ferrite [3]. In particular, $\mathrm{ZnFe}_{2} \mathrm{O}_{4}$ has been one of the first compounds where the HP orthorhombic post-spinel structure has been determined [4]. For this compound, the equation of state $[1,5]$ and other mechanical properties, such as elastic moduli, have been reported [6 - 8].
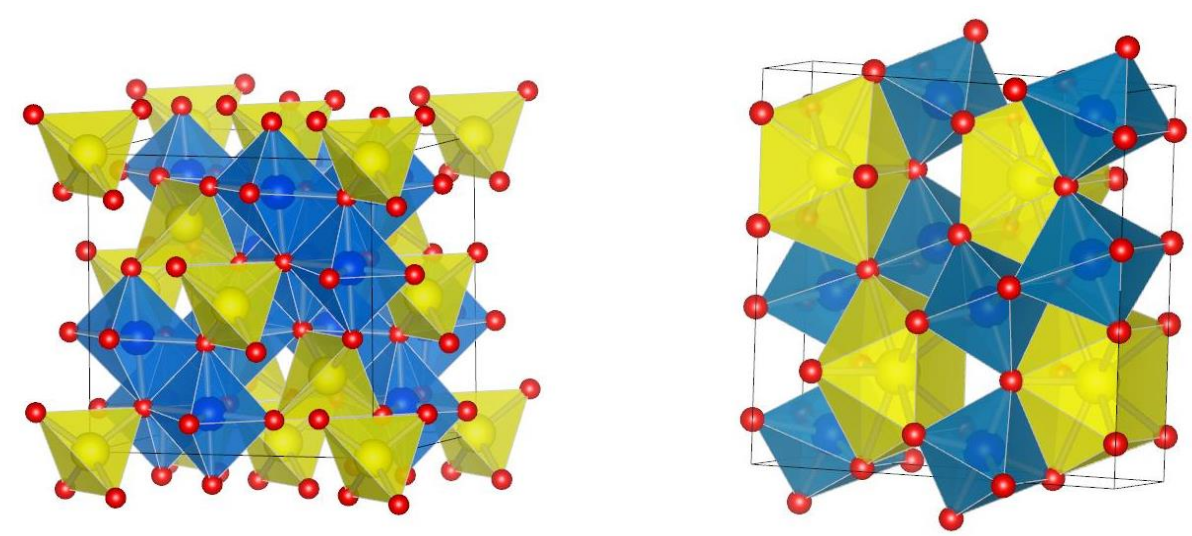

Fig. 1. (Left) Schematic view of the cubic spinel structure of $\mathrm{ZnFe}_{2} \mathrm{O}_{4}$ with octahedral (blue) and tetrahedral (yellow) units. Oxygen atoms are represented in red. (Right) Schematic view of the orthorhombic HP phase $\left(\mathrm{CaMn}_{2} \mathrm{O}_{4}\right.$-like) of $\mathrm{ZnFe}_{2} \mathrm{O}_{4}$ with octahedral (blue) and dodecahedral (yellow) units. Oxygen atoms are also represented in red. Structural representations made with VESTA [9]. 
Although many high-pressure studies have been performed on bulk spinel oxides, investigation of nanoparticles under pressure is scarce. Indeed, one of the few compounds already studied at high pressure in the nanoparticle form is $\mathrm{CoFe}_{2} \mathrm{O}_{4}$ [10]. It is a very wellknown fact, that due to the high surface-to-volume ratio, nanomaterials might show a different high-pressure behavior than bulk materials $[11,12]$. In particular the transitionpressure, the HP structural sequence, and properties like compressibility maybe different. The above described facts suggest that it is important to explore the HP behavior of $\mathrm{ZnFe}_{2} \mathrm{O}_{4}$ nanoparticles to check the structural stability and the possible occurrence of a Hall-Petch strengthening [13]. Hence, we performed synchrotron room-temperature powder X-ray diffraction (XRD) experiments on $\mathrm{ZnFe}_{2} \mathrm{O}_{4}$ nanoparticles up to $47 \mathrm{GPa}$. These studies allowed us to determine the equation of state (EOS) of the low-pressure phase, the identification of a phase pressure-induced transition at $33 \mathrm{GPa}$, and the crystal structure of the HP phase, which is shown on the right side of Fig. 1. For comparison, we further performed similar studies on the low-pressure phase of magnetite $\left(\mathrm{Fe}_{3} \mathrm{O}_{4}\right)$, an inverse spinel, up to 23 GPa. The results obtained for the nanoparticles are compared with the bulk and the highpressure behavior of cobalt ferrite nanoparticles [10].

\section{Experimental details}

Zinc ferrite nanoparticles were synthesized by the sol-gel method and magnetite nanoparticles were synthesized by the co-precipitation method. Details of synthesis as well as the crystal structure and magnetic properties at ambient pressure have been reported elsewhere [14]. The resulting cubic $\mathrm{ZnFe}_{2} \mathrm{O}_{4}$ powder has a unit-cell parameter of $8.439(1) \AA$ and a grain size of $46(3) \mathrm{nm}$. The magnetite powder has a lattice parameter of 8.389(1) $\AA$ and a grain size of 55(9) $\mathrm{nm}$. Room-temperature HP angle-dispersive XRD studies were conducted in a symmetric-type diamond-anvil cell (DAC) with Ne as pressure-transmitting medium (PTM). The diamond cell was equipped with 300 micron-culet diamonds. The 
samples were loaded in a 100 micron-diameter hole of a rhenium gasket pre-indented to a thickness of 30 micron. Synchrotron radiation from beamline 16-IDB of the HPCAT at Advanced Photon Source (Argonne National Laboratory) was used as X-ray source. The applied pressure was determined by the ruby fluorescence technique with an accuracy of 0.05 GPa. The monochromatic $\mathrm{x}$-rays $(\lambda=0.3738 \AA)$ from the beamline were focused using Kirkpatrick-Baez mirrors to $10 \times 10 \mu \mathrm{m}^{2}$. XRD patterns were collected using a Pilatus $1 \mathrm{M}-\mathrm{F}$ detector. For $\mathrm{ZnFe}_{2} \mathrm{O}_{4}$ pressures from $1.3 \mathrm{GPa}$ to $47 \mathrm{GPa}$ (21 steps) were applied during compression, and four pressures $(40.5,34.6,12.1$ and $0.7 \mathrm{GPa})$ were measured during decompression. For magnetite, pressures were applied from $3.6 \mathrm{GPa}$ to $23 \mathrm{GPa}$ (9 steps) during compression using the same experimental set up. In addition, one pressure point was measured at $0.1 \mathrm{GPa}$ after decompression. The two-dimensional XRD images were the integrated with FIT2D [15] into one-dimensional diffraction patterns. The patterns were analyzed using MAUD [16]. The extracted pressure versus unit-cell volume (V) data was analyzed using the EOS-fit [17].

\section{Results and discussion}

\subsection{Zinc Ferrite nanoparticles $(\mathrm{P}<33 \mathrm{GPa})$}

Fig. 2 shows a selection of XRD patterns measured for $\mathrm{ZnFe}_{2} \mathrm{O}_{4}$ nanoparticles up to $47 \mathrm{GPa}$. The patterns indicate that the nanoparticles remain in spinel structure up to 30.4 GPa. At $33 \mathrm{GPa}$ and above, changes in the diffraction patterns showed a phase transition to a HP phase. The crystal-structure identification of such phase will be discussed in the next subsection. In Fig. 2 we show representative XRD patterns (after background subtraction) along with the results of the profile matching analysis and the residuals. As shown in the figure, all the Bragg peaks can be fitted to spinel $\mathrm{ZnFe}_{2} \mathrm{O}_{4}$, ruby (our pressure scale), or $\mathrm{Ne}$ (our pressure medium). The ruby and Ne peaks were used to confirm the pressure determined 
from ruby fluorescence using their P-V EOS $[18,19]$. From the XRD patterns collected (P < $33 \mathrm{GPa}$ ), we have obtained the pressure dependence of the unit-cell parameter and volume of $\mathrm{ZnFe}_{2} \mathrm{O}_{4}$, from multiphase structural analyses, for which the unit-cell parameters, isotropic thermal parameters, scale factors, and shape parameters have been considered as free parameters. For $\mathrm{Ne}$ and ruby peaks a LeBail fit was used. For the Rietveld analysis of $\mathrm{ZnFe}_{2} \mathrm{O}_{4}$, the occupation of the oxygen and cationic positions were assumed based upon stoichiometry. The atomic positions were used from Levy et al. [4] and considered that they are not affected by pressure. This was done to reduce the number of free parameters since only twelve Bragg peaks were measured for the low-pressure phase of $\mathrm{ZnFe}_{2} \mathrm{O}_{4}$ under compression due to the angular constrain imposed by the DAC and the detector. This assumption is reasonable [4] and is common in HP studies, not affecting the determination of the unit-cell parameter [20]. The residuals obtained in the structural analyses indicate that the assumed structural model is reasonable. The goodness-of-fit values of the multiphase profile matching shown for the experiment performed at $30.4 \mathrm{GPa}$ are $\mathrm{R}_{\mathrm{W}}=4.67 \%, \mathrm{R}_{\mathrm{B}}=5.98 \%$, and weighted $\chi^{2}=1.88$. Similar goodness-of-fit values were obtained at all pressures below $33 \mathrm{GPa}$. We would like to mention here that a tetragonal distortion of the cubic spinel structure, observed in other spinels under compression [21], is not observed in our experiments. 


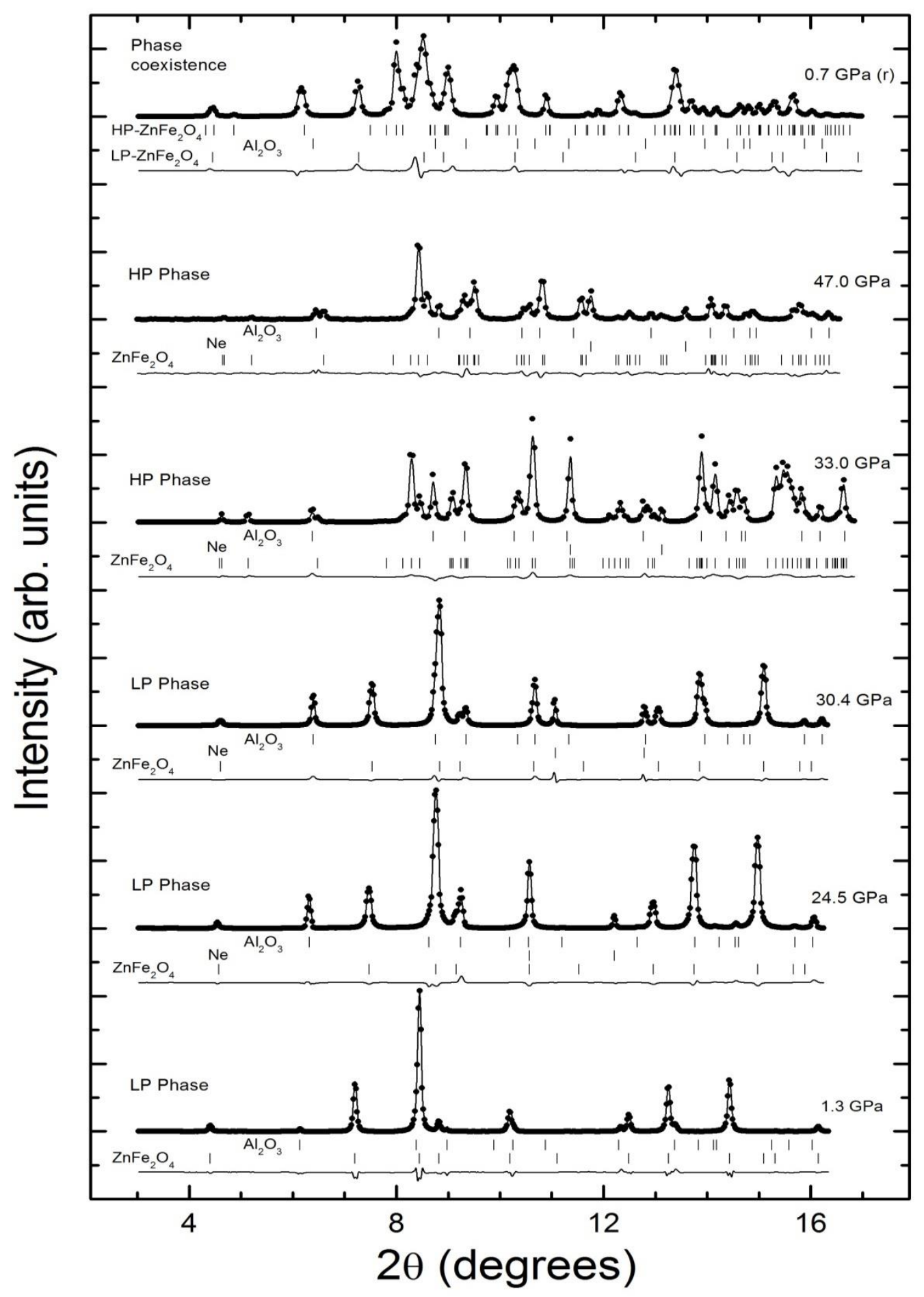

Fig. 2. Experimental $\mathrm{X}$-ray diffraction patterns of $\mathrm{ZnFe}_{2} \mathrm{O}_{4}$ nanoparticle for different pressures (dots) superimposed with calculated profiles (solid lines). Below each pattern the ticks represent the peaks of each crystalline phase found and the solid line represents the difference between experimental and calculated profiles. 
The results obtained for the pressure dependence of the unit-cell volume are shown in Fig. 3. We have used a second (BM2) and a third-order (BM3) Birch-Murnaghan [22] EOS in order to analyze these results. The PTM used for the experiments is known to be a good quasi-hydrostatic medium [23]. However, to confirm that deviatory stresses did not influenced our experiments $[24,25]$, the P-V data were divided for analysis in two sets: the first one, using the measurements for $\mathrm{P}<20 \mathrm{GPa}$, and the second one using all the data available for the cubic spinel phase $(\mathrm{P}<33 \mathrm{GPa})$. Both sets of data were analyzed setting the volume at zero pressure as a free parameter and leaving it as a fixed parameter with a value equal to $600.99 \AA^{3}$. The results of the obtained bulk modulus $(\mathrm{K})$ and first pressure derivative $\left(\mathrm{K}^{\prime}\right)$ are reported in Table 1. 


\begin{tabular}{|c|c|c|c|}
\hline Pressure range & Type of EOS & Fixed Vo & Free $V_{0}$ \\
\hline \multirow[t]{2}{*}{$\mathrm{P}<20 \mathrm{GPa}$} & BM2 & $\begin{array}{l}\mathbf{V}_{0}=600.99 \AA^{3} \\
K=162(4) \mathrm{GPa} \\
\mathrm{K}^{\prime}=4 \text { (implied) } \\
\left(\chi^{2}=1.53\right)\end{array}$ & $\begin{array}{l}\mathrm{V}_{0}=600.5(6) \AA^{3} \\
\mathrm{~K}=169(3) \mathrm{GPa} \\
\mathrm{K}^{\prime}=4 \text { (implied) } \\
\left(\chi^{2}=1.31\right)\end{array}$ \\
\hline & BM3 & $\begin{array}{l}\mathbf{V}_{0}=\mathbf{6 0 0 . 9 9} \AA^{3} \\
K=160(20) \mathrm{GPa} \\
\mathrm{K}^{\prime}=5.1(1.8) \\
\left(\chi^{2}=1.19\right)\end{array}$ & $\begin{array}{l}\mathrm{V}_{0}=600.9(9) \AA^{3} \\
\mathrm{~K}=160(12) \mathrm{GPa} \\
\mathrm{K}^{\prime}=5.1(1.3) \\
\left(\chi^{2}=1.08\right)\end{array}$ \\
\hline \multirow[t]{2}{*}{$\mathrm{P}<33 \mathrm{GPa}$} & BM2 & $\begin{array}{l}\mathbf{V}_{0}=\mathbf{6 0 0 . 9 9} \AA^{\mathbf{3}} \\
\mathrm{K}=165(7) \mathrm{GPa} \\
\mathrm{K}^{\prime}=4 \text { (implied) } \\
\left(\chi^{2}=1.58\right)\end{array}$ & $\begin{array}{l}\mathrm{V}_{0}=601(1) \AA^{3} \\
\mathrm{~K}=165(6) \mathrm{GPa} \\
\mathrm{K}^{\prime}=4 \text { (implied) } \\
\left(\chi^{2}=1.49\right)\end{array}$ \\
\hline & BM3 & $\begin{array}{l}\mathbf{V}_{0}=600.99 \AA^{3} \\
\mathrm{~K}=168(7) \mathrm{GPa} \\
\mathrm{K}^{\prime}=3.7(9) \\
\left(\chi^{2}=1.18\right)\end{array}$ & $\begin{array}{l}\mathrm{V}_{0}=600.4(6) \AA^{3} \\
\mathrm{~K}=173(6) \mathrm{GPa} \\
\mathrm{K}^{\prime}=3.4(8) \\
\left(\chi^{2}=1.10\right)\end{array}$ \\
\hline
\end{tabular}

Table 1. Values of bulk modulus (K), and its first pressure derivative (K') for second-order (BM2) and third-order (BM3) Birch-Murnaghan EOS fitted to different datasets of zinc ferrite nanoparticles. The results were obtained taking the unit-cell volume at ambient pressure $\left(\mathrm{V}_{0}\right)$ as fixed or leaving it as a free parameter. The reduced $\chi^{2}$ of the fits is also given. 
As it can be seen in Table 1, the fits carried out for $\mathrm{P}<20 \mathrm{GPa}$ and $\mathrm{P}<33 \mathrm{GPa}$ give similar reduced $\chi^{2}$. In addition, the values obtained for $\mathrm{K}$ and $\mathrm{K}$ ' for the two pressure regions were similar if error bars are considered. In particular, the $\mathrm{K}$ and $\mathrm{K}^{\prime}$ values determined from the $3^{\text {rd }}$ order EOS for P $<33 \mathrm{GPa}$ lies within the $1 \sigma$ confidence ellipse obtained from the fit made for $\mathrm{P}<20 \mathrm{GPa}$. These facts confirm that the effect of deviatory stresses in our experiments can be considered negligible, as expected from the used PTM. Furthermore, the fits made using $\mathrm{V}_{0}$ as a free parameter or as a fixed parameter gave similar results for $\mathrm{K}$ and $\mathrm{K}$ ' that agree within the standard deviations. The same can be said when the BM2 and BM3 EOS are compared. A comparison of the BM3 EOS $\left[\mathrm{V}_{0}=600.4(6) \AA^{3}, \mathrm{~K}=173(6) \mathrm{GPa}, \mathrm{K}^{\prime}=\right.$ 3.4(8)] for the LP phase is shown in Fig.3. The maximum pressure difference between the fit and the experiments is smaller than $0.5 \mathrm{GPa}$.

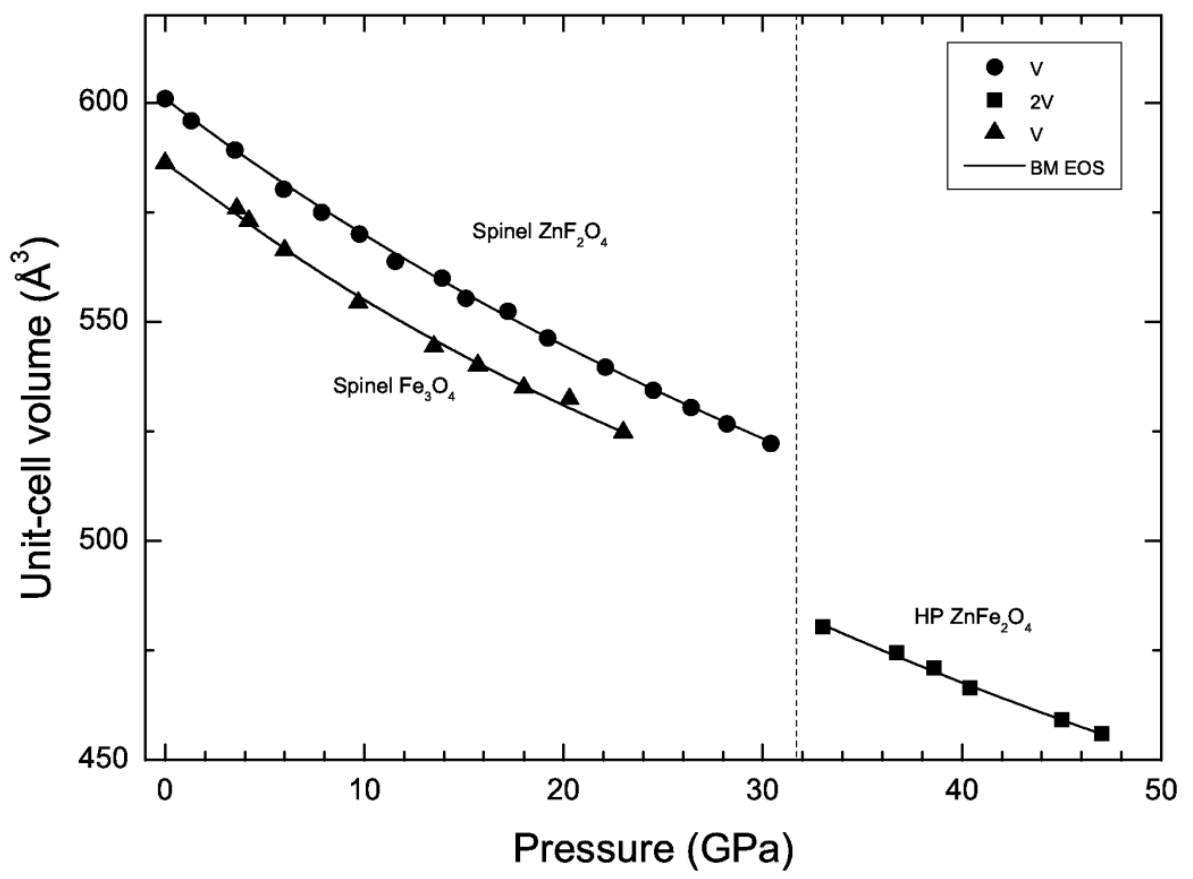

Fig. 3. Unit-cell volume vs pressure for $\mathrm{ZnFe}_{2} \mathrm{O}_{4}$ nanoparticle powder (circles: LP phase, squares: $\mathrm{HP}$ phase) and $\mathrm{Fe}_{3} \mathrm{O}_{4}$ nanoparticle powder (triangles) together with the 3rd order Birch-Murnaghan fit (solid line). For the HP phase $2 \mathrm{~V}$ is plotted instead of $\mathrm{V}$ to facilitate the comparison and the 2nd order EOS is shown (3rd order EOS was not fit, see text). 
In Table 2, we have compared the results of our BM3 fit ( $\mathrm{V}_{0}$ not fixed) with the literature. The average value of the bulk modulus obtained for bulk $\mathrm{ZnFe}_{2} \mathrm{O}_{4}$ is 180 (14) $\mathrm{GPa}$, which agree within error bars with our value $[\mathrm{K}=173(6) \mathrm{GPa}]$. The same can be seen for different values of $\mathrm{K}$ from the fits reported in Table 1. As it can be seen from Table 2, the bulk modulus obtained is slightly smaller than those previously reported, except from the results by Levy et al. [4] ( $\mathrm{K}=166 \mathrm{GPa})$. At the same time, it should be mentioned that the bulk modulus derivative $K^{\prime}=9.3(6)$ [4] is much larger than our value of $K^{\prime}=3.4(8)$. This could be due to the lack of hydrostatic conditions in the reported experiments [4]. Also it is important to mention that Levy et al. used data below $24.4 \mathrm{GPa}$ for the fit. Ultrasonic measurements in a natural Mn-rich franklinite mineral [6] have shown a bulk modulus closer to our result, but the deviation in $\mathrm{K}$ maybe due to the Mn content [6]. A comparison with the rest of the results summarized in Table 2 indicates that the predicted Hall-Petch strengthening does not occur in $\mathrm{ZnFe}_{2} \mathrm{O}_{4}$ nanoparticles.

\begin{tabular}{|c|c|c|c|}
\hline $\mathbf{K}(\mathbf{G P a}), \mathbf{K}^{\prime}($ dimensionless $)$ & Sample form & Method & Ref. \\
\hline 193, - & Single crystal & Infrared & {$[7]$} \\
\hline $182,-$ & Single crystal & Ultrasonic & {$[8]$} \\
\hline $175(3), 4.3(3)$ & Mn-rich natural mineral & 1 Ultrasonic & {$[6]$} \\
\hline 166(3), 9.3(6) & Powder & BM3 EOS & [4] \\
\hline 185(9), 3.1(7) & Powder & BM3 EOS & {$[5]$} \\
\hline $173(6), 3.4(8)$ & Nanoparticles & BM3 EOS & Present \\
\hline
\end{tabular}

Table 2. Values of bulk modulus $K$ and bulk modulus first derivative $K^{\prime}$ of zinc ferrite samples cited in literature compared with our results. 


\subsection{Zinc Ferrite nanoparticles $(\mathrm{P} \geq 33 \mathrm{GPa})$}

In Fig. 2 it can be seen that at $33 \mathrm{GPa}$ and above, the Bragg peaks obtained for the sample cannot be indexed with the cubic-spinel zinc ferrite structure. The changes in the XRD patterns are consistent with the occurrence of a pressure-driven phase transition. Previously, a structural phase transition was reported to occur in bulk $\mathrm{ZnFe}_{2} \mathrm{O}_{4}$ above $24 \mathrm{GPa}$ [4] and in the range of $25-36 \mathrm{GPa}$ [5]. Our transition pressure is within the transition pressure range reported in Ref. [5]. Therefore, apparently, the transition pressure of the cubic spinel zinc ferrite does not depend much upon the particle size. Indeed, as pointed out by Greenberg et al. [5] the differences observed in the EOS parameters and transition pressures between the results reported by Levy et al. [4] with Greenberg's and our results "could be due to the lack of hydrostatic conditions using $\mathrm{N}_{2}$ as pressure medium above $\mathrm{P}>12 \mathrm{GPa}$ " in Ref. [4] In fact, it is known that non-hydrostatic conditions could strongly influence more the HP behavior of ternary oxides than the particle size [26, 27].

Regarding the crystal structure of the HP phase, in the literature $[4,5,21]$ there are basically three candidates for the post-spinel structure: $\mathrm{CaTi}_{2} \mathrm{O}_{4}$-type (space group $\mathrm{Cmcm}$ ), $\mathrm{CaFe}_{2} \mathrm{O}_{4}$-type (space group Pnam), and $\mathrm{CaMn}_{2} \mathrm{O}_{4}$-type (space group $\mathrm{Pbcm}$ ) structures. We tested these three structures as the possible $\mathrm{HP}$ structure of the $\mathrm{ZnFe}_{2} \mathrm{O}_{4}$ nanoparticles. We found that the last one is the only structure among the three that can explain all the XRD peaks of the new HP phase. The structural analyses were carried out using the procedure already described for the low-pressure phase. In this case, for the atomic position we used those reported for $\mathrm{CaMn}_{2} \mathrm{O}_{4}$ by Zouari et al. [28] assuming that $\mathrm{Zn}$ (Fe) replaces $\mathrm{Ca}(\mathrm{Mn})$. The small residuals obtained at 33 and $47 \mathrm{GPa}$, show that the $\mathrm{CaMn}_{2} \mathrm{O}_{4}$-type structure can reproduce the XRD patterns measured from the HP phase of our sample. The goodness-of-fit values of the multiphase profile matching of the experiment performed at $33 \mathrm{GPa}$ are $\mathrm{R}_{\mathrm{W}}=$ $4.81 \%, \mathrm{R}_{\mathrm{B}}=6.12 \%$, and weighted $\chi^{2}=1.95$. Thus, apparently the HP structure is different 
in nanoparticles than in the bulk material, where the $\mathrm{CaTi}_{2} \mathrm{O}_{4}$-type structure has been assigned to the $\mathrm{HP}$ phase of $\mathrm{ZnFe}_{2} \mathrm{O}_{4}$ [4]. The unit-cell parameters obtained for the orthorhombic structure at $33 \mathrm{GPa}$ are $a=2.746(2) \AA, b=9.431(9) \AA$, and $c=9.274(9) \AA$. The HP structure is illustrated in the right side of Fig. 1. Similar qualities of refinements were obtained at all the pressures for the HP orthorhombic structure. Upon decompression we observed that the phase transition is not completely reversible. At 40.5 and $34.6 \mathrm{GPa}$ only the HP phase was detected. However, at 12.1 and $0.7 \mathrm{GPa}$ a mixture of the high- and lowpressure phases was found. Fig. 2 shows the XRD pattern measured after decompression at 0.7 GPa. The result of a LeBail fit is shown to illustrate the phase coexistence. The pressure dependence obtained for the unit-cell volume and parameters is shown in Figs. 3 and 4.

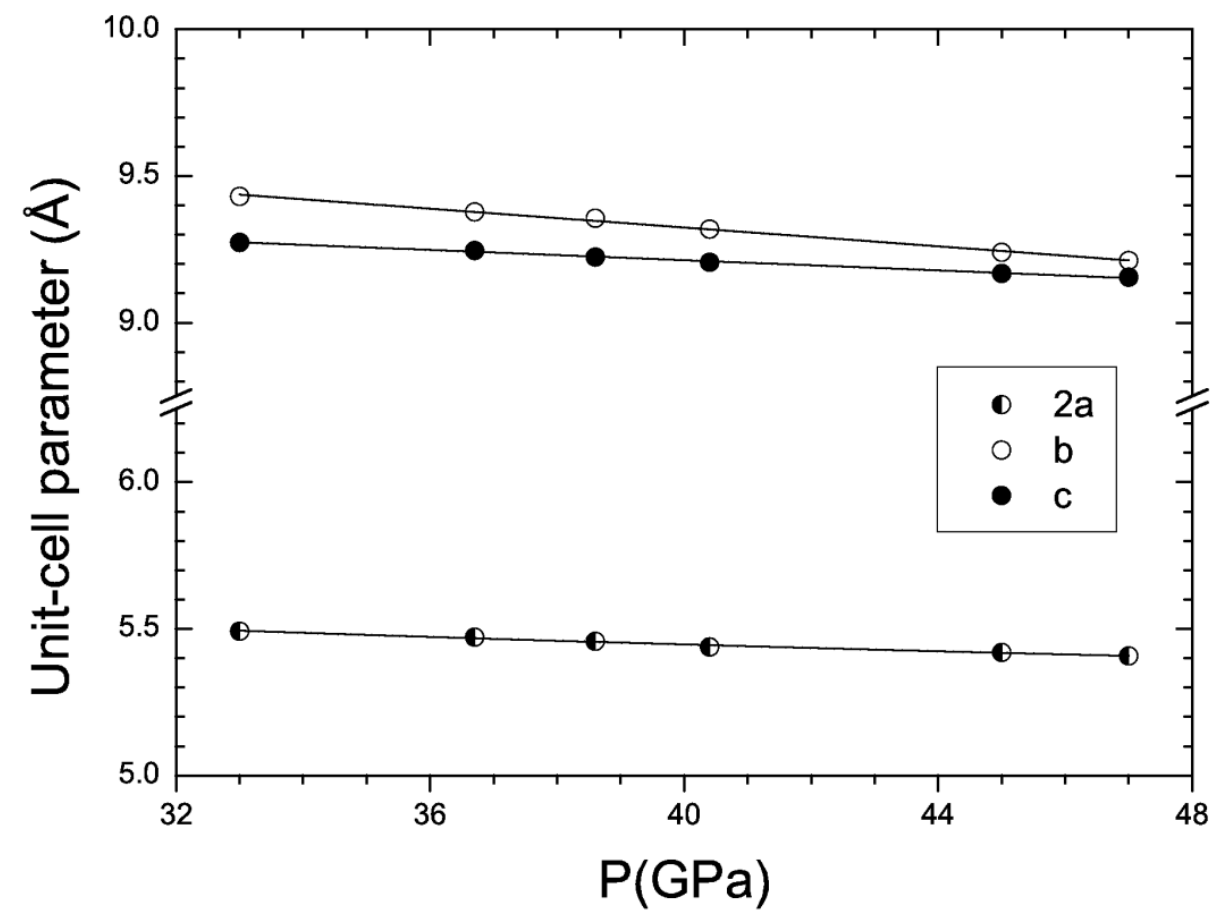

Fig. 4. Unit-cell parameters of $\mathrm{HP}$ phase $\left(\mathrm{CaMn}_{2} \mathrm{O}_{4}\right.$-like $)$ of $\mathrm{ZnFe}_{2} \mathrm{O}_{4}$ vs. pressure. Note that $2 a$ is plotted instead of $a$ to facilitate comparison.

The cubic-orthorhombic transition involves an increase of the density of material $(8 \%)$ as a consequence of the volume collapse that can be seen in Fig. 3. It also involves an increase of the $\mathrm{Zn}^{2+}$ coordination from fourfold to eightfold, while retaining the $\mathrm{Fe}^{3+}$ 
coordination. The coordination change maybe significant, and should be confirmed by full structural refinements, if possible carried out from HP single-crystal experiments [27]. However, the bond distances and angles obtained from the HP phase here proposed are reasonable when compared with HP phases reported for other spinels [2], which support our conclusions.

We have analyzed the P-V data by fitting with a second-order Birch-Murnaghan EOS. We have used this EOS because there are only few pressure points measured after the structural phase transition. In addition, we fixed the ambient pressure volume of the HP phase to the volume determined at $0.7 \mathrm{GPa}$ from the LeBail fit; $\mathrm{V}_{0}=271 \AA^{3}$. We found that the bulk modulus $\mathrm{K}=182(12) \mathrm{GPa}$, with the reduced $\chi^{2}=2.18$. Thus, the HP orthorhombic phase has a similar bulk modulus than the low-pressure cubic spinel phase. This is the first report of the bulk modulus of $\mathrm{HP}$ phase of $\mathrm{ZnFe}_{2} \mathrm{O}_{4}$ as far as we know. Other aspect that we would like to discuss here is the linear compressibility of the different axes of the HP structure. As it can be seen from Fig. 4, the compressibility is anisotropic in the HP phase. In particular, the $b$-axis is the most compressible one. Adjusting with a linear regression the unit-cell parameters we determined that: $a=2.85(1) \AA$ - 0.0034(2) $\AA / \mathrm{GPa}$. P; $b=9.96(3) \AA$ $0.0160(5) \AA / G P a$. P; and $c=9.56(3) \AA-0.0087(2) \AA / G P a$. P. From these linear functions we obtained the axial compressibility, $\kappa_{x}=\frac{-1}{x} \frac{\partial x}{\partial P}$, where $\kappa_{\mathrm{a}}=1.2(1) \times 10^{-3} \mathrm{GPa}^{-1}, \kappa_{\mathrm{b}}=$ 1.6(1) $\times 10^{-3} \mathrm{GPa}^{-1}$, and $\kappa_{\mathrm{c}}=0.9(1) \times 10^{-3} \mathrm{GPa}^{-1}$. Extrapolating our results to higher pressures we found that at $\sim 55 \mathrm{GPa} b$ becomes equal to $c$. This suggests that the HP orthorhombic structure will probably undergo a phase transition to a tetragonal structure at much higher pressure. Future experiments are needed in order to confirm or rule out this prediction. 


\subsection{Magnetite nanoparticles}

The compressibility of magnetite has been investigated earlier (see ref. [29]). A good compilation of reported bulk modulus values is provided in Table 2 of Ref. [30]. It is worth to notice that all previous studies were only performed in bulk samples. Here, we report results obtained from nanoparticles. The other objective of our measurement was to compare the compressibility of a normal cubic spinel $\left(\mathrm{ZnFe}_{2} \mathrm{O}_{4}\right)$ with an inverse spinel $\left(\mathrm{Fe}_{3} \mathrm{O}_{4}\right)$ and hence we have constrained our experiments to $23 \mathrm{GPa}$. However, it is worth to mention that a previous study [31] has reported a high-pressure modification of $\mathrm{Fe}_{3} \mathrm{O}_{4}$ with a $\mathrm{CaMn}_{2} \mathrm{O}_{4}$-type structure, as observed in our experiments for $\mathrm{ZnFe}_{2} \mathrm{O}_{4}$.

All of the peaks from the XRD patterns of magnetite nanoparticles we have measured at different pressures up to $23 \mathrm{GPa}$ can be assigned to cubic spinel structure. This is no surprise since the HP modification of bulk magnetite has been observed only above $25 \mathrm{GPa}$ $[30,32]$. Using the Rietveld method we obtained the unit-cell parameter of $\mathrm{Fe}_{3} \mathrm{O}_{4}$ at different pressures. In Fig. 3, we show the pressure evolution of the unit-cell volume. Applying a thirdorder Birch-Murnaghan EOS to these results we have determined an ambient pressure volume $\mathrm{V}_{0}=590.4(9) \AA^{3}$, a bulk modulus of $\mathrm{K}=152(9) \mathrm{GPa}$, and its first pressure derivative $\mathrm{K}^{\prime}=5.2(1.3)$ with the reduced $\chi^{2}=1.93$. This is lower than the bulk modulus obtained for zinc ferrite nanoparticles in the range $\mathrm{P}<22 \mathrm{GPa}$.

The bulk modulus $(\mathrm{K}=152(9) \mathrm{GPa}$ ) of nanoparticles falls in the low range of bulk $\mathrm{Fe}_{3} \mathrm{O}_{4}$ from XRD experiments, which range from 144 to $222 \mathrm{GPa}$ [30]. However, accurate quasi-hydrostatic single-crystal XRD measurements reported for natural magnetite showed K $=180(1) \mathrm{GPa}$ and $\mathrm{K}^{\prime}=5.4(4)$ and ultrasonic measurements showed $\mathrm{K}=186(3) \mathrm{GPa}$ and $\mathrm{K}^{\prime}=$ 5.1(1). These bulk modulus are nearly $20 \%$ larger than our bulk modulus. Consequently, our measurements indicate that $\mathrm{Fe}_{3} \mathrm{O}_{4}$ nanoparticles do not undergo Hall-Petch strengthening. 
In conclusion our experiments showed that the fact that $\mathrm{Fe}_{3} \mathrm{O}_{4}$ and $\mathrm{ZnFe}_{2} \mathrm{O}_{4}$ nanoparticles do not undergo a Hall-Petch strengthening. This fact contrasts with our recent findings on partially inverse $\mathrm{CoFe}_{2} \mathrm{O}_{4}$ spinel nanoparticles. In this case, the bulk modulus of the nanoparticles $(\mathrm{K}=204 \mathrm{GPa})$ is considerably larger than the value previously reported for bulk $\mathrm{CoFe}_{2} \mathrm{O}_{4}(\mathrm{~K}=172 \mathrm{GPa})$ [10]. It is known that the particle size could strongly influence the compressibility of nanoparticles, as shown for anatase-type $\mathrm{TiO}_{2}$ [33]. . In addition to particle size, there are other facts that could influence the HP behavior of nanoparticles; one of them is the PTM used in the experiments. Depending on the PTM, pressure gradients and deviatory stresses might be different; influencing the physical state of the studied sample [34- 35]. In addition, the interaction between the nano-crystalline sample and the PTM due to the high surface-to-volume ratio of nanomaterials and the tendency of nanoparticles to aggregate needs to be studied [12]. Further studies on $\mathrm{CoFe}_{2} \mathrm{O}_{4}$ under similar experimental conditions as reported for $\mathrm{ZnFe}_{2} \mathrm{O}_{4}$ and $\mathrm{Fe}_{3} \mathrm{O}_{4}$ could provide more details.

\section{Conclusions}

In this work, we report a room-temperature XRD study on nanoparticles of $\mathrm{ZnFe}_{2} \mathrm{O}_{4}$ and $\mathrm{Fe}_{3} \mathrm{O}_{4}$ under compression using synchrotron radiation. Samples used for the experiments were synthesized and characterized at ambient pressure (before HP experiments) using a combination of techniques. For the two compounds we determined the effect of pressure in the cubic spinel structure and a P-V EOS. For both, $\mathrm{ZnFe}_{2} \mathrm{O}_{4}$ and $\mathrm{Fe}_{3} \mathrm{O}_{4}$ nanoparticles, we have observed the absence of a Hall-Petch strengthening. On the other hand, changes observed in the XRD patterns of $\mathrm{ZnFe}_{2} \mathrm{O}_{4}$ indicate the occurrence of a structural phase transition for pressures above $33 \mathrm{GPa}$. This post-spinel transition is not fully reversible after decompression. We found that the orthorhombic $\mathrm{CaMn}_{2} \mathrm{O}_{4}$-type structure describes well the XRD patterns of the HP phase of $\mathrm{ZnFe}_{2} \mathrm{O}_{4}$. The axial compressibility for the HP phase is also reported. We found that the compression of this phase is anisotropic, being the $b$-axis the 
most compressible one. In addition, under compression the $b$ - and the $c$-axes became gradually equal, suggesting a possible phase transition to a tetragonal structure near $55 \mathrm{GPa}$. The EOS for the HP phase is also reported, the HP phase of $\mathrm{ZnFe}_{2} \mathrm{O}_{4}$ has a similar bulk modulus that the low-pressure spinel phase.

\section{Acknowledgments}

S.F., F.G. and F.D.S. thanks the financial support provided by the Agencia Nacional de Proyectos en Ciencia y Técnica (ANPCyT) under grant PICT-2012-1730. D.E. thanks the financial support provided by the Spanish government MINECO under Grant No: MAT201346649-C4-1-P and MAT2015-71070-REDC. XRD experiments were performed at HPCAT (Sector 16), Advanced Photon Source (APS), Argonne National Laboratory. HPCAT operations are supported by DOE-NNSA under Award No. DE-NA0001974 and DOE-BES under Award No. DE-FG02-99ER45775, with partial instrumentation funding by NSF. APS is supported by DOE-BES, under Contract No. DE-AC02-06CH11357. 


\section{References}

[1] M.G. Brik, A. Suchocki, A. Kaminska, Inorg. Chem. 53 (2014) 5088.

[2] Pressure-Induced Phase Transitions in $\mathrm{AB}_{2} \mathrm{X}_{4}$ Chalcogenide Compounds, D. Errandonea, in Springer Series in Materials Science: $\mathrm{AB}_{2} \mathrm{O}_{4}$ Compounds at High Pressures, Vol. 189, Ch. 2, edited by F.J. Manjon, I. Tiginyanu, V. Ursaki (Springer-Verlag, Berlin - Heidelberg, 2014). DOI: 10.1007/978-3-642-40367-5.

[3] Y. Goto, Jap. J. Appl. Phys. 3 (1964) 309.

[4] D. Levy, A. Pavese, M. Hanfland, Phys. Chem. Minerals 27 (2000) 638.

[5] E. Greenberg, G.Kh. Rozenberg, W. Xu, R. Arielly, M.P. Pasternak, A. Melchior, G. Garbarino, L.S. Dubrovinsky, High Press. Res. 29 (2009) 764.

[6] H. J. Reichmann, S. D. Jacobsen, T. B. Ballaran, Am. Mineral. 98 (2013) 601.

[7] N.W. Grimes, Phys. Stat. Sol. (b) 58 (1973) 1521.

[8] Z. Li, E.S. Fisher, Jour. Mat. Sci. Lett. 9 (1990) 759.

[9] K. Momma, F. Izumi, J. Appl. Crystallogr., 44 (2011) 1272.

[10] F.D. Saccone, S. Ferrari, D. Errandonea, F. Grinblat, V. Bilovol, S. Agouram, J. Appl. Phys. 118 (2015) 075903.

[11] A. San Miguel, Chem. Soc. Rev. 35 (2006) 876.

[12] C. Popescu, J.A. Sans, D. Errandonea, A. Sergura, R. Villanueva, F. Sapiña, Inorg. Chem. 53 (2014) 11598.

[13] C.E. Carlton, P.J. Ferreira. Acta Materialia 55 (2007) 3749.

[14] S. Ferrari, J.C. Aphesteguy, F.D. Saccone, IEEE Transaction on Magnetics 51 (2015) 2900206.

[15] A.P. Hammersley, S.O. Svensson, M. Hanfland, A.N. Fitch, D. Häusermann, High Press. Res. 14 (1996) 235. 
[16] L. Lutterotti, M. Bortolotti, G. Ischia, I. Lonardelli, H.-R. Wenk, Z. Kristallogr. 26 (2007), 125.

[17] R. J. Angel, J. Gonzalez-Platas, M. Alvaro M, Zeitschrift für Kristallog. 229 (2014) 405. [118] A. Dewaele, M. Torrent, Phys. Rev. B 88 (2013) 064107.

[19] A. Dewaele, F. Datchi, P. Loubeyre, and M. Mezouar, Phys. Rev. B 77 (2008) 094106.

[20] D. Errandonea, C. Ferrer Roca, D. Martinez Garcia, A. Segura, O. Gomis, A. Muñoz, P. Rodriguez-Hernandez, J. Lopez-Solano, S. Alconchel, F. Sapiña, Phys. Rev. B 82 (2010) 174105.

[21] D. Errandonea, R. S. Kumar, F. J. Manjon, V. V. Ursaki, E. V. Rusu, Phys. Rev. B 79 (2009) 024103.

[22] F. Birch, J. Geophys. Res. 91 (1986) 4949.

[23] S. Klotz, J.C. Chervin, P. Munsch, G.L. Marchand, J. Phys. D: Appl. Phys. 42 (2009) 075413.

[24] D. Errandonea, A. Muñoz, J. Gonzalez-Platas, J. Appl. Phys. 115 (2014) 216101.

[25] O. Gomis, J. A. Sans, R. Lacomba-Perales, D. Errandonea, Y. Meng, J.C. Chervin, A. Polian, Phys. Rev. B 86 (2012) 054121.

[26] A. B. Garg, D. Errandonea, P. Rodriguez-Hernandez, S. Lopez-Moreno, A. Muñoz, C. Popescu, J. Phys.: Condens. Matter 26 (2014) 265402.

[27] D. Errandonea, Crystal Res. and Tech. 50 (2015) 729.

[28] S. Zouari, L. Ranno, A. Cheikh-Rouhou, O. Isnard, M. Pernet, P. Wolfers, P. Strobel, J. Alloys Compd. 353 (2003) 5.

[29] E. Madelung, R. Fuchs, Analen der Physik Leipzig Folge 465 (1921) 289.

[30] C. Haavik, S. Stølen, H. Fjellvåg, M. Hanfland, D. Häusermann, Am. Mineral. 85 (2000) 514. 
[31] Y. Fei, D. J. Frost, H. K. Mao, C. T. Prewitt, D. Häusermann, Am. Mineral. 84 (1999) 203.

[32] H. K. Mao, T. Takahashi, W.A. Bassett, G. L. Kinsland, L. Merrill, Jour. Geoph. Res. 79 (1974) 1165.

[33] Y. Al-Khatatbeh, K. K. Lee, B. Kiefer, J. Phys. Chem. C 116 (2012) 21635.

[34] D. Santamaria-Perez, L. Gracia, G. Garbarino, A. Beltran, R. Chulia-Jordan, O. Gomis, D. Errandonea, Ch. Ferrer-Roca, D. Martinez-Garcia, A. Segura, Phys. Rev. B 84 (2011) 054102.

[35] D. Errandonea, Y. Meng, M. Somayazulu, D. Häusermann, Physica B 355 (2005) 116. 


\section{Graphical Abstract}

Phase transition induced by pressure in $\mathrm{ZnFe}_{2} \mathrm{O}_{4}$ nanocrystals

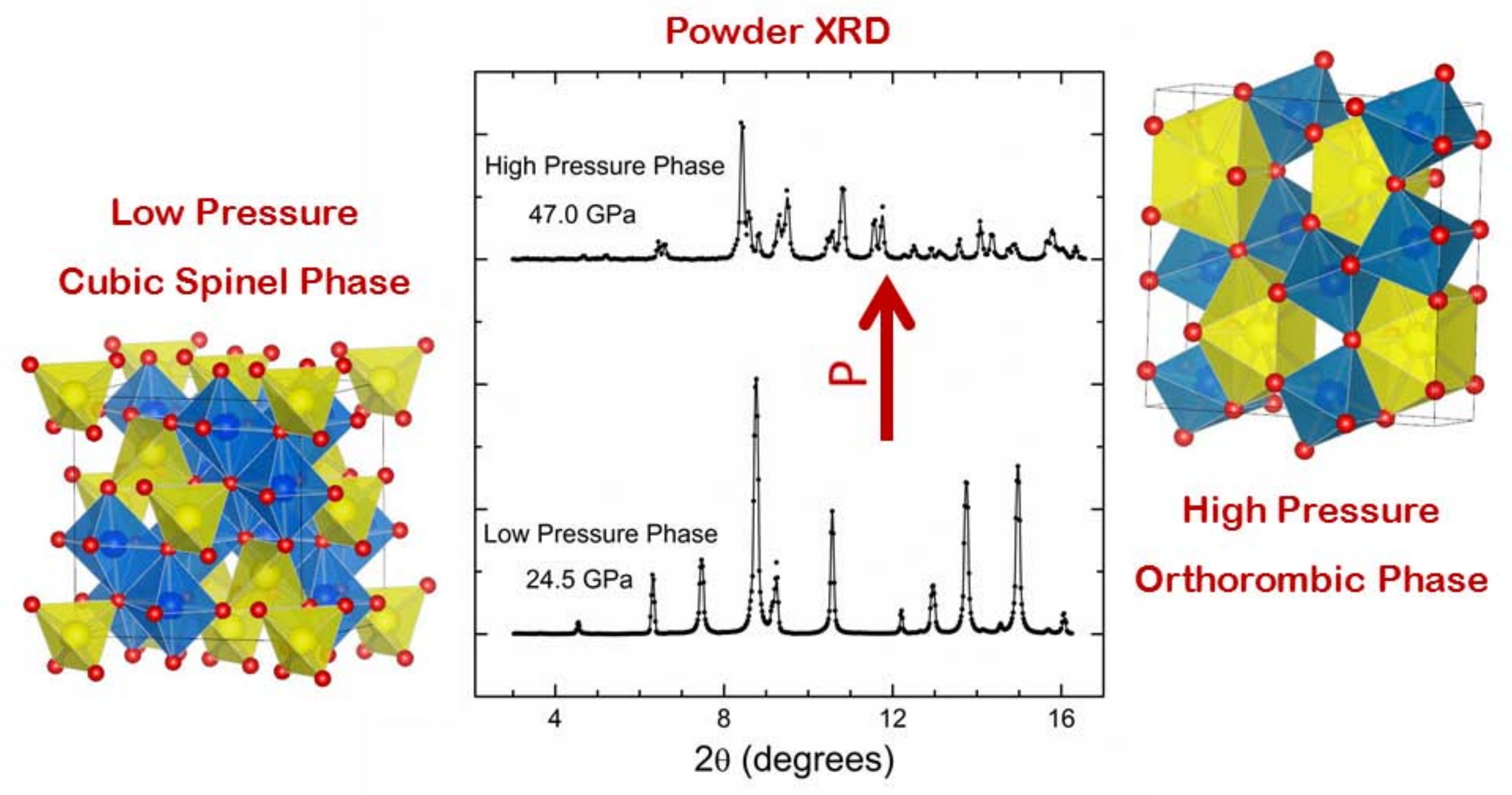

